\title{
Palladium nanoparticles stabilized in block-copolymer micelles for highly selective 2-butyne-1,4-diol partial hydrogenation
}

\author{
Natalia Semagina $^{\mathrm{a}, 1}$, Eric Joannet ${ }^{\mathrm{a}}$, Sandra Parra ${ }^{\mathrm{a}}$, \\ Esther Sulman $^{\mathrm{b}}$, Albert Renken ${ }^{\mathrm{a}}$, Lioubov Kiwi-Minsker ${ }^{\mathrm{a}, *}$ \\ ${ }^{a}$ Laboratory of Chemical Reaction Engineering, Swiss Federal Institute of Technology, LGRC-EPFL, CH-1015 Lausanne, Switzerland \\ ${ }^{\mathrm{b}}$ Tver Technical University, Russia
}

Received 19 August 2004; received in revised form 1 October 2004; accepted 3 October 2004

Available online 8 January 2005

\begin{abstract}
Pd nanoparticles $(2 \mathrm{~nm}$ ) stabilized in the micelle core of poly(ethylene oxide)-block-poly-2-vinylpyridine were studied in 2-butyne-1,4diol partial hydrogenation. Both unsupported micelles $\left(0.6 \mathrm{~kg} \mathrm{Pd}_{\mathrm{P}} / \mathrm{m}^{3}\right)$ and supported ones on $\gamma-\mathrm{Al}_{2} \mathrm{O}_{3}(0.042$ wt. $\%$ Pd $)$ showed nearly $100 \%$ selectivity to 2-butene-1,4-diol up to $94 \%$ conversion. The only side product observed was 2-butane-1,4-diol. The catalysis was ascribed to Pd nanoparticles' surface modified by pyridine units of micelles and alkali reaction medium (pH of 13.4). TOFs over the unsupported and supported catalysts were found to be 0.56 and $0.91 \mathrm{~s}^{-1}$ (at $323 \mathrm{~K}, 0.6 \mathrm{MPa} \mathrm{H}_{2}$ pressure, solvent 2-propanol/water = 7:3), respectively. Reaction kinetics fit the Langmuir-Hinshelwood model assuming weak hydrogen adsorption. The experiments on the catalyst reuse showed that Pd nanoparticles remain inside the micelle core, but the micelles slightly desorbed (less then 5\%) during the catalytic run.
\end{abstract}

(C) 2004 Elsevier B.V. All rights reserved.

Keywords: Palladium; Nanoparticle; Alkyne alcohol hydrogenation; Micelle catalysis

\section{Introduction}

During the last years, much attention has focused on the catalytic application of metal nanoparticles due to their unique physical and chemical properties, which are distinct both from the bulk phase and from isolated atoms [1-4]. Catalytic properties of metal nanoparticles are a function of their size, crystal lattice parameters and chemical environment surrounding the nanoparticle [4].

Formation of metal nanoparticles is commonly carried out by reduction of metal ions in the presence of a stabilizer like linear polymers [1], surfactants [5,6], and heterogeneous supports, which prevent the nanoparticles from aggregation [7]. A great challenge is to design a highly selective active phase comprising an ensemble of metal atoms [8] in the presence of stabilizers. The nanocatalyst

\footnotetext{
* Corresponding author. Tel.: +41 21693 3182; fax: +41 216933190 E-mail address: lioubov.kiwi-minsker@epfl.ch (L. Kiwi-Minsker).

${ }^{1}$ On leave from the Tver Technical University.
}

prepared with functional polymers allow the size control of the metal nanocrystallites, and the tailoring environment by the polymer nature [9]. However, homopolymers do not possess any nanostructure and show a restricted ability of particles' stabilization [10]. The amphiphilic block copolymers are known to form micelles and can provide enhanced control over metal particles' nucleation and growth [11].

The application of micelles in catalysis is described in the scientific literature [12-16]. This approach [12] allows separation by ultrafiltration [13] or by pressure/temperature variation when supercritical $\mathrm{CO}_{2}$ is used as a reaction media [14]. The surfactant usually has a catalytically active group or solubilizes a homogeneous catalyst $[1,15,17]$.

For about a decade, the stabilization of metal nanoparticles' by micelles has been investigated. Studies have found an inhibiting effect of surfactants on particles' catalytic activity $[6,18]$. The surfactant removal after the micelles immobilization onto solid supports significantly increases the catalytic activity, but the main advantage of micellar 
catalysis, i.e., the improvement of the catalyst performance due to the specific medium [13] is lost. Tsang et al. [19] developed the deposition of Pd nanoparticles over the polyoxyethylene stearyl ether and used these particles for catalytic applications. Mayer and Mark [20] reported both the preparation of noble-metal colloids in the micellar corona of polystyrene-block-poly(ethylene oxide) and polystyrene-block-poly(methacrylic acid) with polystyrene core and their activity in cyclohexene hydrogenation. Seregina et al. [21] developed monometallic and bimetallic colloids stabilized in the micellar core of polystyrene-blockpoly-4-vinylpyridine (PS-b-P4VP) in toluene for hydrogenations. The same metal-polymer systems were studied by some of us in partial hydrogenation of acetylene alcohol (dehydrolinalool with terminal triple bond) [22,23] and showed selectivity above $99 \%$. Pyridine is known [24] to increase selectivity in alkyne hydrogenation to alkene due to the increased metal electron density leading to decreased alkene adsorption. Hence, the pyridine units in the micellar core are responsible for the formation of highly selective catalytic particles due to the induced electronic effect [22]. The drawback of the PS-b-P4VP block copolymer is the use of toluene as solvent with related environmental impact. Therefore, the poly(ethylene oxide)-block-poly-2-vinylpyridine (PEO-b-P2VP) micelles were proposed for $\mathrm{Pd}$ nanoparticle formation and catalytic application in wateralcohol solvent for dehydrolinalool hydrogenation [25].

This study is focusing on the application of Pd nanoparticles stabilized in PEO-b-P2VP micelles for selective hydrogenation of acetylene alcohol 2-butyne-1,4-diol (B3). Moreover, for the first time we show that the micellar nanocatalyst can be immobilized and reused. The basic $\gamma-\mathrm{Al}_{2} \mathrm{O}_{3}$ containing hydroxyl groups [26] is often used as support for the hydrogenation catalysts $[21,22,24,27]$ and therefore was employed by us in this work. The hydrogenation product 2-butene-1,4-diol (B2) is industrially important since it is used as an intermediate in the production of endosulfan, vitamins $A$ and $B_{6}$, as well as in the paper, textile and resin industries $[28,29]$.

\section{Experimental}

\subsection{Materials}

PEO-b-P2VP $\quad\left(M_{\mathrm{n}}^{\mathrm{PEO}}=9000, \quad M_{\mathrm{n}}^{\mathrm{P} 2 \mathrm{VP}}=4300, \quad M_{\mathrm{w}} /\right.$ $M_{\mathrm{n}}=1.05$ ) was purchased from Polymer Source, Inc., Canada, and used as received. $\mathrm{K}_{2} \mathrm{PdCl}_{4}$ and $\mathrm{NaBH}_{4}$ were received from Aldrich and used without purification. 2-Butyne-1,4-diol (puriss. crystallized $\geq 99.0 \%$, GC), cis-2butene-1,4-diol (purum $\geq 96 \%$, GC), 2-propanol (99.5\% grade, HPLC), potassium hydroxide $(\geq 85 \%)$ were purchased from Fluka, Switzerland. Hydrogen $(\geq 99.99 \%$ purity) was from Carbagas, Switzerland, $\gamma-\mathrm{Al}_{2} \mathrm{O}_{3}$ was supplied by Engelhard Corporation. Bidistilled water was used for all the experiments.

\subsection{Catalyst preparation}

Synthesis of Pd nanoparticles stabilized in the core of PEO-b-P2VP micelles was performed in aqueous medium as described in [25]. First, $0.2240 \mathrm{~g}$ of PEO-b-P2VP was dissolved in $40 \mathrm{ml}$ of water and stirred for $24 \mathrm{~h}$. Then, the solution was charged with $0.0750 \mathrm{~g}$ of $\mathrm{K}_{2} \mathrm{PdCl}_{4}$ and stirred for $48 \mathrm{~h}$. To ensure the absence of the salt outside of the micelle cores, reaction solution was ultrafiltrated. Reduction of Pd ions was carried out by addition of a two-fold excess of an aqueous $\mathrm{NaBH}_{4}$ solution $(1 \mathrm{~g} / \mathrm{l})$ prepared directly before use. After that, solution was ultrafiltrated to remove impurities and finally its volume was set at $40 \mathrm{ml}$.

Reduction with $\mathrm{NaBH}_{4}$ leads to the nanoparticles formation of $2 \mathrm{~nm}$ diameter. Complete $\mathrm{Pd}$ incorporation and stabilization into P2VP core has been reported in [30]. Pd loading in the colloidal catalyst was $0.6 \mathrm{~kg} / \mathrm{m}^{3}$ as confirmed by AAS.

The supported catalyst was prepared by incipient wetness impregnation of the powdered $\gamma-\mathrm{Al}_{2} \mathrm{O}_{3}(60 \mu \mathrm{m})$ with the colloidal catalyst to obtain Pd loading of $4.2 \times 10^{-2} \mathrm{wt} . \%$ for a typical hydrogenation experiment and $2.8 \times 10^{-2} \mathrm{wt} . \%$ for a Madon-Boudart test [31]. As the immobilized micelles contain the reduced $\mathrm{Pd}$, no additional reduction was performed. The supported catalyst was dried in vacuum (600 mbar) for $1 \mathrm{~h}$ at room temperature, followed by heating (3 $\mathrm{K} / \mathrm{min}$ ) to $80^{\circ} \mathrm{C}$ and keeping for $1 \mathrm{~h}$. The temperature of $80{ }^{\circ} \mathrm{C}$ was chosen to avoid degradation of PEO at higher temperatures [32]. Catalysts are air-stable and can be stored for a long time without any special precautions.

\subsection{Methods of characterization}

The BET specific surface area and pore size distribution (PSD) of the support and the catalyst were determined using a Sorptomatic 1990 (Carlo Erba) instrument via $\mathrm{N}_{2}$ adsorption-desorption at $77 \mathrm{~K}$. PSD calculation was performed by Dollimore/Heal method [33].

The specific surface area of Pd and Pd-dispersion were measured by pulse adsorption of $\mathrm{CO}(3 \% \mathrm{CO}$ in $\mathrm{He})$ performed at $323 \mathrm{~K}$ via AutoChem 2910 (Micromeritics, USA). Before the measurements, samples were pretreated in the flow of $\mathrm{He}(10 \mathrm{ml} / \mathrm{min}, \mathrm{STP})$ at $423 \mathrm{~K}$ and reduced in a flow of $\mathrm{H}_{2}(20 \mathrm{ml} / \mathrm{min}, \mathrm{STP})$ at $423 \mathrm{~K} \mathrm{[34]}$. A stoichiometry of $\mathrm{CO} / \mathrm{Pd}=0.6$ and a Pd surface density of $1.2 \times 10^{19}$ atoms/ $\mathrm{m}^{2}$ [35] was used for calculations.

Pd amount was determined by atomic absorption spectroscopy (AAS) at $247.6 \mathrm{~nm}$ via Perkin Elmer Atomic Absorption Spectrometer 1100A instrument supplied with a Pd hollow cathode lamp as a radiation source.

Ultrafiltration of the reaction mixture containing unsupported catalyst was performed using the Amicon stirred cell 8200 (Millipore) supplied with an ultrafiltration membrane (pore size of $5000 \mathrm{Da}$ at $1 \mathrm{bar}$ ).

$\mathrm{GC}$ analysis of the reaction mixture samples was performed using Auto System XL (Perkin Elmer) equipped with $30 \mathrm{~m}$ 
Perkin Elmer Elite Series $0.25 \mathrm{~mm}$ capillary column with a $0.25-\mu \mathrm{m}$ coating, at temperature ramp of $20^{\circ} \mathrm{C} / \mathrm{min}$ from 100 to $220^{\circ} \mathrm{C}$ as described in [34]. Butane-1,3-diol was used as the internal standard for quantitative GC analysis.

\subsection{Catalytic experiments}

Hydrogenations were carried out in a batch stainless steel reactor (150 $\mathrm{ml}$ autoclave, Buchi AG, Uster, Switzerland) equipped with a heating jacket, stirrer (8-blade disk turbine impeller) and a hydrogen supply system [34]. At the working temperature the reactor was filled with the reaction mixture and the catalyst, flushed with $\operatorname{Ar}(0.8 \mathrm{MPa})$ and kept for $10 \mathrm{~min}$ under stirring to equalize temperature. Then the reactor was flushed with hydrogen and pressurized. During the course of the reaction, the pressure in the reactor was maintained constant. The samples of the reaction mixtures were periodically withdrawn from the reactor via a sampling tube and analyzed by GC.

The initial reaction mixture was prepared by dissolution of $\mathrm{B} 3$ in $100 \mathrm{~mL}$ of solvent $(30 \mathrm{~mL}$ of water and $70 \mathrm{~mL}$ of 2-propanol), and $\mathrm{pH}$ of 13.4 was set by addition of $17.8 \mathrm{kmol} / \mathrm{m}^{3} \mathrm{KOH}$ solution. This medium allows avoiding mass transfer limitations inside the PEO-P2VP-Pd micelle [25]. B3 concentrations were $0.1,0.25$ and $0.5 \mathrm{kmol} / \mathrm{m}^{3}$; catalyst amount in a typical hydrogenation experiment was equal to $4.2 \times 10^{-3} \mathrm{~kg}_{\mathrm{Pd}} / \mathrm{m}^{3}$ in the reaction mixture $(0.7 \mathrm{~mL}$ of the unsupported catalyst, or $1 \mathrm{~g}$ of the heterogeneous catalyst).

The kinetic reaction regime was ensured by an intensive stirring of $1000 \mathrm{rpm}$ avoiding external diffusion limitations. Besides, the kinetic regime was confirmed experimentally by the Madon-Boudart test using the catalysts with different Pd loading and equal dispersions and is described below [31].

For reuse of the unsupported catalyst, the reaction mixture was ultrafiltrated, the residual solution $(2 \mathrm{~mL})$ was rinsed with a solvent, diluted to $100 \mathrm{~mL}$, and used again. The supported catalyst was filtered, rinsed with water and dried.

\section{Results and discussion}

\subsection{Catalyst characterization}

The representative scheme of the unsupported catalytic system is shown in Fig. 1 [25,36]. Detailed physicochemical characterization of this catalyst was reported [25,30]. As was shown in [21] by XPS, only $\mathrm{Pd}(0)$ obtained by $\mathrm{NaBH}_{4}$ reduction exists in the vinylpyridine core of micellar catalyst.

After impregnation of $\gamma-\mathrm{Al}_{2} \mathrm{O}_{3}\left(153 \mathrm{~m}^{2} / \mathrm{g}\right)$ and drying, the specific surface area increased up to $204 \mathrm{~m}^{2} / \mathrm{g}$ due to the presence of polymeric chains, which are known to possess high surface areas [37]. A slight decrease of the average pore diameter (from 35.9 to $30.2 \AA$ ) was observed suggesting that pore blocking does not take place. As reported in [30], the mean micelle diameter is $81 \mathrm{~nm}$, thus, the micelles are

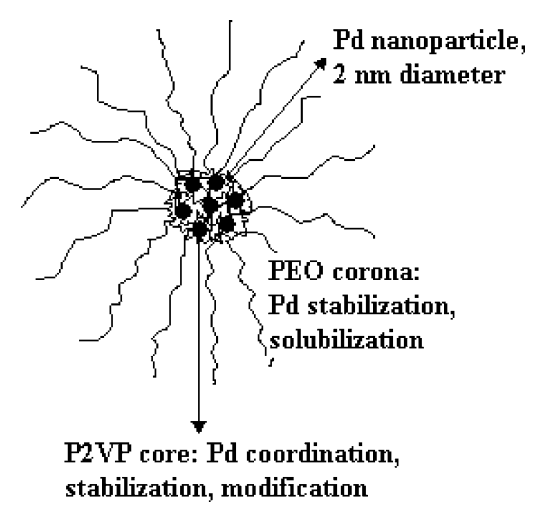

Fig. 1. Schematic presentation of a micellar catalyst: Pd nanoparticles formed in block copolymer micelle of PEO-P2VP.

adsorbed onto the support external surface, probably, via hydrogen bonding of $\mathrm{OH}$ groups.

Pd dispersion in the supported catalyst was found $~ 54 \%$ (the particle diameter of $2.1 \mathrm{~nm}$ ). Nanoparticle size did not change with respect to the unsupported catalyst (2 $\mathrm{nm}$ [30]) indicating the metal stabilization in the micellar core and the absence of the particles' agglomeration during the immobilization process. Besides, this stability remained during the catalyst pretreatment in hydrogen flow applied before $\mathrm{CO}$ chemisorption. TEM images of the supported catalyst could not be recorded because of the low Pd content $\left(4.2 \times 10^{-2}\right.$ wt. $\left.\%\right)$.

\subsection{Hydrogenation kinetics}

\subsubsection{Verification of the kinetic regime for the supported catalyst}

The external mass transfer limitations were avoided by stirring at $1000 \mathrm{rpm}$. The effect of catalyst loading on catalytic activity was studied at $323 \mathrm{~K}$, at $\mathrm{H}_{2}$ pressure of $0.6 \mathrm{MPa}$ and initial B3 concentration of $0.25 \mathrm{kmol} / \mathrm{m}^{3}$. The reaction rate was found two-fold higher $( \pm 7 \%)$, when the catalyst loading was increased from 0.05 to $0.1 \mathrm{~kg} / \mathrm{m}^{3}$, confirming the absence of the external diffusion limitations.

To ensure kinetic regime, two catalysts with Pd loading of $4.2 \times 10^{-2}$ and $2.8 \times 10^{-2}$ wt. \% were used to apply the Madon-Boudart test [31]. It should be noted that the Pd dispersion in the two catalysts is the same as found with unsupported catalyst (see Section 3.1). Two catalysts with different Pd loading exhibited the same TOF value of $0.86 \pm 0.06 \mathrm{~s}^{-1}$ confirming the kinetic regime. TOF was expressed as amount of moles of B3 converted (using the initial reaction rate) over one active site (surface Pd atom) per second. The number of active sites of the supported catalyst was calculated on the basis of Pd dispersion of $53.9 \%$ as determined by $\mathrm{CO}$ chemisorption.

\subsubsection{Catalytic activity of the unsupported and supported catalysts}

The kinetic curves of B3 consumption over the unsupported and supported catalysts at $323 \mathrm{~K}, 0.25 \mathrm{kmol} / \mathrm{m}^{3} \mathrm{~B} 3$ 


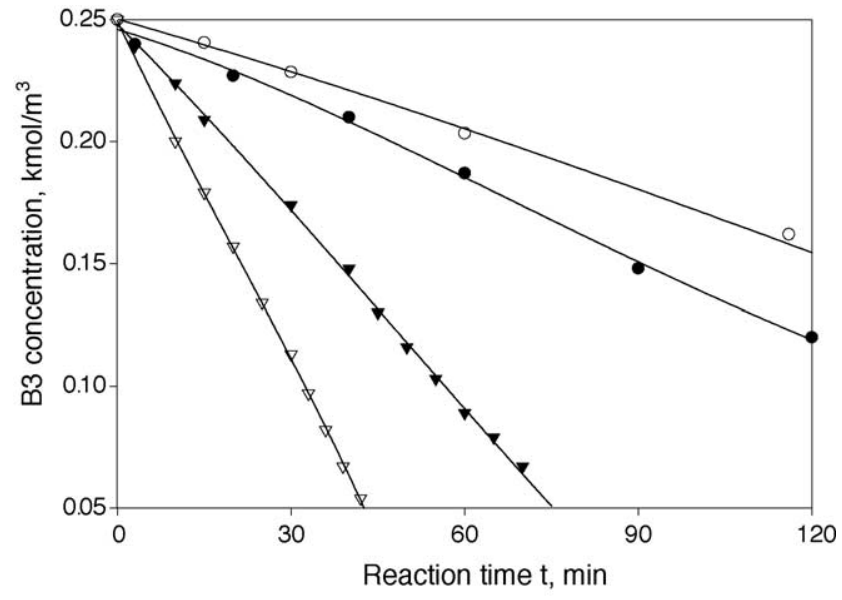

Fig. 2. 2-Butyne-1,4-diol concentration as function of time for the reactions over the unsupported catalyst $(\mathrm{O})$ at $0.6 \mathrm{MPa} \mathrm{H}_{2}$ pressure, and for all the supported one at $(\bigcirc) 0.6 \mathrm{MPa},(\nabla) 1.0 \mathrm{MPa},(\nabla) 2.0 \mathrm{MPa}$. Reaction conditions: $0.25 \mathrm{kmol} / \mathrm{m}^{3} \mathrm{~B} 3$, solvent $(100 \mathrm{~mL})$ : $70 \mathrm{vol} . \%$ 2-propanol in water, pH $13.4,323 \mathrm{~K}$, catalyst amount of $4.2 \times 10^{-3} \mathrm{~kg}_{\mathrm{Pd}} / \mathrm{m}^{3}, 1000 \mathrm{rpm}$.

concentration, and the catalyst amount of $4.2 \times 10^{-3} \mathrm{~kg}_{\mathrm{Pd}} / \mathrm{m}^{3}$ are presented in Fig. 2. Analogous concentration time profiles were reported for $\mathrm{B} 3$ hydrogenation over $\mathrm{Pd}$ deposited on activated carbon fibers [38] and over $1 \% \mathrm{Pd} /$ $\mathrm{CaCO}_{3}$ catalyst modified with ammonia [28], and correspond to the Langmuir-Hinshelwood mechanism. The initial TOF values of the unsupported and supported catalysts at $0.6 \mathrm{MPa}$ hydrogen pressure were found to be 0.56 and $0.91 \mathrm{~s}^{-1}$, respectively. The activity improvement after the micelles' immobilization by a factor of 1.6 corresponds to the value of 1.7 reported by Seregina et al. [21] for cyclohexene hydrogenation in toluene over unsupported and supported Pd colloids stabilized by polystyrene-block-poly-4-vinylpyridine; such a behavior is attributed to the electron transfer induced by the alumina support.

Catalytic experiments were also performed to study the effect of pressure (Fig. 2). Linear dependence of the initial reaction rates on the hydrogen pressure (Fig. 3) indicates first order with respect to hydrogen being in line with the results reported in [33]. This can be attributed to a low nanoparticle surface coverage by hydrogen $[38,39]$.

\subsubsection{Selectivity to 2-butene-1,4-diol}

Both unsupported and supported catalysts exhibit selectivity to B2 close to $100 \%$ up to $94 \%$ conversion. For example, in a typical hydrogenation experiment at $0.6 \mathrm{MPa}$ using the supported catalyst, selectivity was found to be $100 \%$ up to $80 \%$ conversion, $99.8 \pm 0.2 \%$ from 80 to $94 \%$ conversion and decreased to $91 \%$ at close to $100 \%$ of 2-butyne-1,4-diol conversion. Fig. 4 shows the selectivity and B2 yield plotted versus conversion: up to almost $100 \%$ conversion the only side product found was 2-butane-1,4diol (B1). No B2 isomerisation to $\gamma$-hydroxybutyraldehyde was observed, which can undergo further hydrogenation-

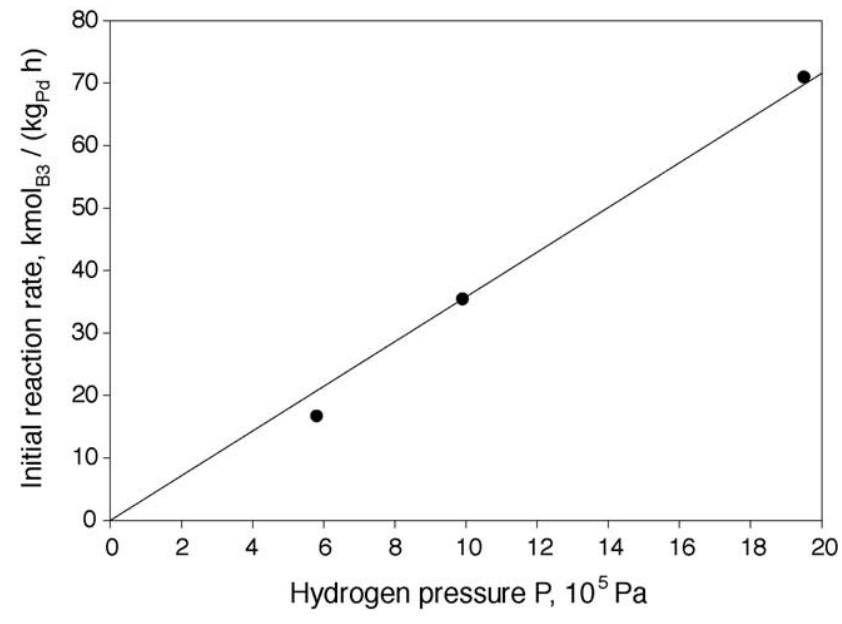

Fig. 3. Initial reaction rate as function of hydrogen pressure (for the supported catalyst). For the reaction conditions, see Fig. 2.

dehydration to butyraldehyde and butanol. This was due to the alkali added to the reaction mixture known to eliminate an acid-catalyzed isomerization [27]. The low yield of the saturated diol from B2 may be attributed to the modification of Pd nanoparticle with pyridine units, as well as to the presence of base in the reaction mixture $[40,41]$.

\subsubsection{Kinetic modeling}

The plot of the substrate and the reaction product's concentrations as a function of time is shown in Fig. 5a. The general shape of kinetic curves obtained for the reactions over the unsupported and supported catalysts is identical. Therefore, the same kinetic model is proposed for both systems. GC analysis of all the samples obtained after B3 hydrogenation showed only B2 formation until 94\% conversion. Beyond this conversion limit, the saturation of the double bond takes place yielding B1. Other products (e.g., $n$-butanol [38]) were not detected in the reaction mixture. Thus, B2 hydrogenation to B1 is suggested as a

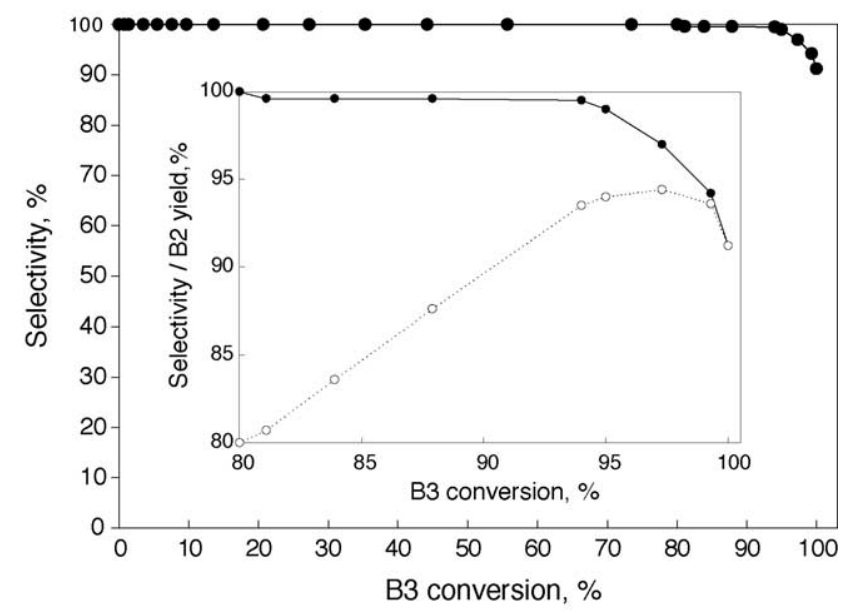

Fig. 4. Selectivity $(\bigcirc)$ and B2 yield $(\bigcirc)$ vs. conversion for hydrogenation reaction over the supported catalyst. Reaction conditions: $0.5 \mathrm{kmol} / \mathrm{m}^{3} \mathrm{~B} 3$, 0.6 MPa, for other conditions see Fig. 2. 

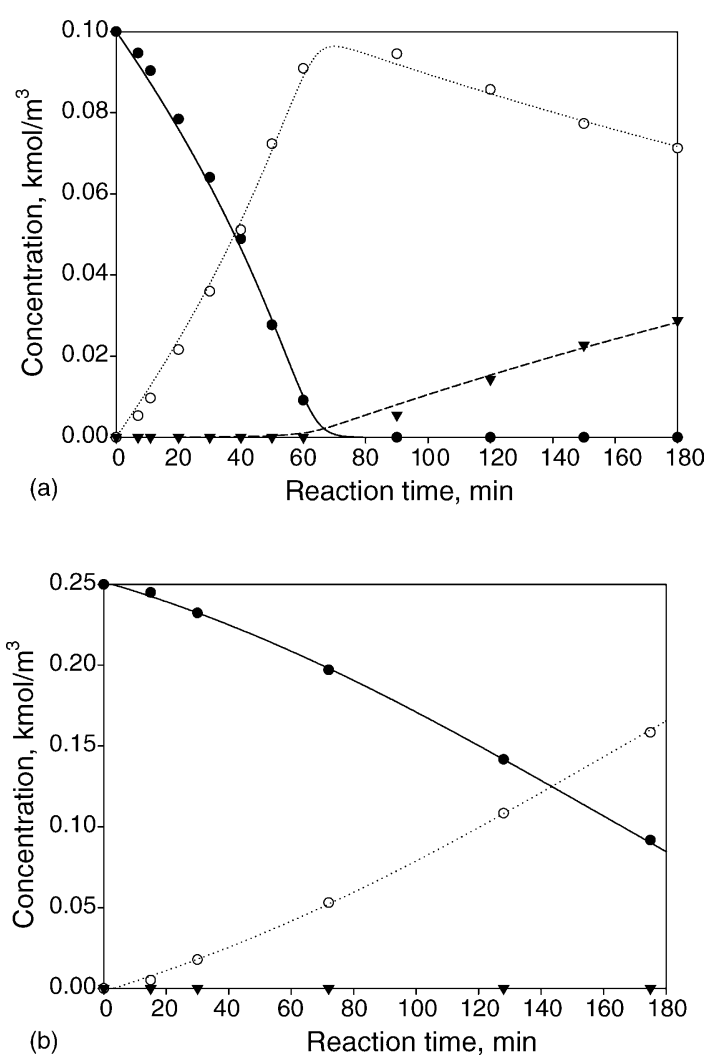

Fig. 5. Measured (points) and predicted (lines) substrate and product concentrations as function of time for the supported (a) and unsupported (b) catalysts: $(\bigcirc) \mathrm{B} 3,(\mathrm{O}) \mathrm{B} 2,(\boldsymbol{\nabla}) \mathrm{B} 1$. Reaction conditions: 0.6 MPa, other see Fig. 2.

consecutive step in the reaction network:

$\mathrm{B} 3 \stackrel{+\mathrm{H}_{2} ; k_{1}^{\prime}}{\longrightarrow} \mathrm{B} 2 \stackrel{+\mathrm{H}_{2} ; k_{2}^{\prime}}{\longrightarrow} \mathrm{B} 1$

Using the equations proposed previously [38], and assuming the Langmuir-Hinshelwood mechanism with weak hydrogen adsorption, the following rate equations are considered:

$r_{1}=\frac{k_{1} C_{\mathrm{B} 3}}{\left(1+K_{\mathrm{B} 3} C_{\mathrm{B} 3}+K_{\mathrm{B} 2} C_{\mathrm{B} 2}+K_{\mathrm{B} 1} C_{\mathrm{B} 1}\right)^{2}}$,

$r_{2}=\frac{k_{2} C_{\mathrm{B} 2}}{\left(1+K_{\mathrm{B} 3} C_{\mathrm{B} 3}+K_{\mathrm{B} 2} C_{\mathrm{B} 2}+K_{\mathrm{B} 1} C_{\mathrm{B} 1}\right)^{2}}$

where $k_{1}=k_{1}^{\prime} K_{\mathrm{B} 3} K_{\mathrm{H}_{2}} C_{\mathrm{H}_{2}}, k_{2}=k_{2}^{\prime} K_{\mathrm{B} 2} K_{\mathrm{H}_{2}} C_{\mathrm{H}_{2}}\left(K_{\mathrm{Bi}}\right.$ and $K_{\mathrm{H}_{2}}$ are the adsorption equilibrium constants of organic species and hydrogen, respectively). The dissolved hydrogen concentration is included in $k_{1}$ and $k_{2}$ as the $\mathrm{H}_{2}$ pressure is held constant. The observed first order with respect to hydrogen corresponds to the proposed model.

The mass balances are given by the differential equations (3a)-(3c):

$$
\begin{aligned}
& \frac{\mathrm{d} C_{\mathrm{B} 3}}{\mathrm{~d} t}=-\frac{m_{\mathrm{cat}}}{V_{\mathrm{L}}} r_{1}, \\
& \frac{\mathrm{d} C_{\mathrm{B} 2}}{\mathrm{~d} t}=\frac{m_{\mathrm{cat}}}{V_{\mathrm{L}}}\left(r_{1}-r_{2}\right),
\end{aligned}
$$

$\frac{\mathrm{d} C_{\mathrm{B} 1}}{\mathrm{~d} t}=\frac{m_{\mathrm{cat}}}{V_{\mathrm{L}}} r_{2}$,

where $m_{\text {cat }}$ is the catalyst mass and $V_{\mathrm{L}}$ is a volume of liquid phase in the reactor.

Model calculations were performed via the Rosenbrock method using the Berkeley Madonna Software [42]. The proposed kinetic model fits well the experimental data both for the unsupported and supported catalysts (Fig. 5). The adsorption equilibrium constant of B3 was found to be 100fold higher than that one for $\mathrm{B} 2$ and conforms to the known higher adsorption equilibrium constant of acetylene alcohols in comparison with ethylene ones [24] and is in good agreement with recent data [34,38].

\subsubsection{Activation energy}

Catalytic experiments were conducted at a temperature variation from 303 to $343 \mathrm{~K}$ at hydrogen pressure of $0.6 \mathrm{MPa}$ and catalyst amount $4.2 \times 10^{-3} \mathrm{~kg}_{\mathrm{Pd}} / \mathrm{m}^{3}$. For each temperature $k_{1}$ value was calculated. Activation energies found from the Arrhenius plots (Fig. 6) were 30 and $36 \mathrm{~kJ} / \mathrm{mol}$ for the reactions over the unsupported and supported catalysts, respectively, indicating once again the absence of mass transport effects. This value is close to the one reported for heterogeneous B3 hydrogenation [28]. As discussed by Seregina et al. [21], the difference in catalytic behavior of the unsupported and supported micellar catalyst may be due to the electron transfer induced by the alumina support leading to the change in the activation energy.

\subsection{Catalyst reuse}

The unsupported catalyst was reused after separation by ultrafiltration and showed the same selectivity and the reaction rate as the fresh one (within the relative error of $<1 \%$ ). No Pd leaching from the micelles was detected indicating the micelle and nanoparticle stability due to the synthesis procedure used [30].

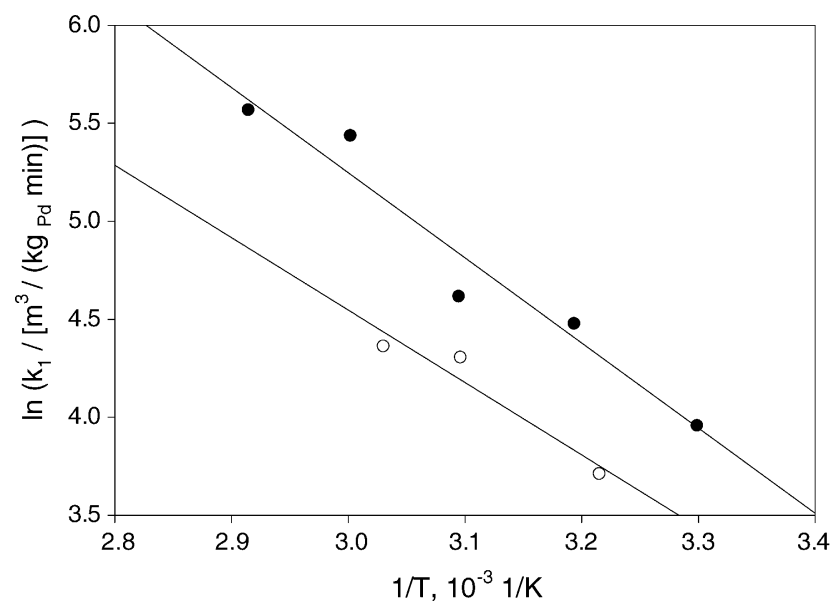

Fig. 6. Arrhenius plots of 2-butyne-1,4-diol hydrogenation over unsupported $(\bigcirc)$ and supported $(\bigcirc)$ catalysts. Reaction conditions: hydrogen pressure 0.6 MPa, other see Fig. 2. 


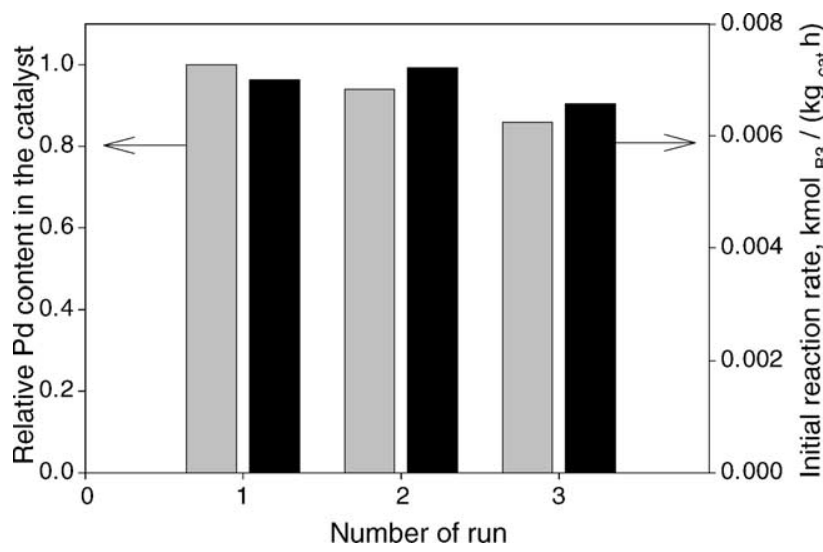

Fig. 7. The reuse of the supported catalysts: $(\square)$ relative Pd content (per initial loading) and ( $\boldsymbol{\square}$ ) initial reaction rates calculated per $\mathrm{kg}_{\text {cat }}$. Reaction conditions: hydrogen pressure 0.6 MPA, others see Fig. 2.

Two experiments were carried out for the reuse of supported catalyst. Fig. 7 shows the initial reaction rates calculated per $\mathrm{kg}$ of the catalyst and the relative Pd content in the catalyst before each run ( $\mathrm{Pd}$ content in the fresh catalyst was assigned to 1.0). In spite of some leaching of Pd-containing micelles $(<5 \%)$ detected by AAS of the reaction mixtures after filtration, no changes were observed in the initial reaction rate which was equal to $0.0069 \pm 0.0003 \mathrm{kmol}_{\mathrm{B} 3} /\left(\mathrm{m}^{3} \mathrm{~h}\right)$, but the selectivity over reused catalyst slightly decreased (e.g., the third run is characterized by $98 \%$ selectivity at $80 \%$ conversion). The $\mathrm{Pd}$ dispersion after the first run was found to be the same as in the fresh catalyst indicating the nanoparticles' resistance to agglomeration inside the micellar core. Usually leaching out of active component reduces the catalytic activity during successive runs [43], unless the catalyst activates under the working conditions. The increase of the supported catalyst performance during reuse might be caused by the changes in the polymer (micelles) morphology [44] over support, which influences both the activity and selectivity [25]. However, the mechanism of such activation is not well understood at the present moment.

\section{Conclusions}

- Highly selective and active catalyst for the 2-butyne-1,4diol partial hydrogenation was developed based on Pd nanoparticles stabilized in micellar core of poly(ethylene oxide)-block-poly-2-vinylpyridine $(0.042 \mathrm{wt} . \% \mathrm{Pd})$ in unsupported form and supported on $\gamma-\mathrm{Al}_{2} \mathrm{O}_{3}$.

- Pyridine units of micellar core and $\mathrm{KOH}$ added to the reaction mixture gave high selectivity (near $100 \%$ up to 94\% conversion) avoiding the use of hazardous additives (pyridine, ammonia, etc.).

- The reaction kinetics fits the Langmuir-Hinshelwood model with weak hydrogen adsorption.

- TOFs at hydrogen pressure of 0.6 MPa and $323 \mathrm{~K}$ over the unsupported and supported catalysts were found to be
0.56 and $0.91 \mathrm{~s}^{-1}$. The activation energies were 30 and $36 \mathrm{~kJ} / \mathrm{mol}$, respectively.

- Reused micellar catalyst showed the stable activity indicating the Pd nanoparticles' stability inside the micellar core.

- Supported catalysts showed some micelle desorption $(<5 \%$ during reaction run) from the alumina. The catalytic activity per gram of the reused catalyst did not decrease suggesting the catalyst activation under working environment.

\section{Acknowledgements}

The work was financed by the Swiss National Science Foundation. N.S. and E.S. thank the Program "NATO Science for Peace" (SfP-974173) for financial support. V. Zhirov is kindly acknowledged for the preparation of unsupported catalyst.

\section{References}

[1] Y. Li, E. Boone, M.A. El-Sayed, Langmuir 18 (2002) 4921.

[2] C.-B. Hwang, Y.-S. Fu, Y.-L. Lu, S.-W. Jang, P.-T. Chou, C.R.C. Wang, S.J. Yu, J. Catal. 195 (2000) 336.

[3] J.W. Yoo, D.J. Hathcock, M.A. El-Sayed, J. Catal. 214 (2003) 1

[4] M. Kralik, A. Biffis, J. Mol. Catal. A 177 (2001) 113.

[5] H. Bonnemann, W. Brijoux, A. Schulze Tilling, K. Siepen, Top. Catal. 4 (1997) 217.

[6] M. Boutonnet, J. Kizling, R. Tourode, G. Maire, P. Stenius, Appl. Catal. 20 (1986) 163.

[7] A. Horvath, A. Beck, A. Sarkany, L. Guczi, Solid State Ionics 148 (2002) 219.

[8] H.H. Kung, M.C. Kung, Appl. Catal. A 246 (2003) 193.

[9] T. Teranishi, M. Miyake, Chem. Mater. 10 (1998) 594.

[10] A. Mayer, M. Antonietti, Col. Polym. Sci. 276 (1998) 769.

[11] M. Moffitt, L. McMahon, V. Pessel, A. Eisenberg, Chem. Mater. 7 (1995) 1185

[12] G. Oehme, I. Grassert, E. Paetzold, R. Meisel, K. Drexler, H. Fuhrmann, Coord. Chem. Rev. 185-186 (1999) 585.

[13] J.H.M. Heijnen, V.G. de Bruijn, L.J.P. van den Broeke, J.T.F. Keurentjes, Chem. Eng. Proc. 42 (2003) 223.

[14] H.G. Niessen, A. Eichhorn, K. Woelk, J. Bargon, J. Mol. Catal. A 182183 (2002) 463.

[15] G. Oehme, I. Grassert, S. Ziegler, R. Meisel, H. Fuhrmann, Catal. Today 42 (1998) 459.

[16] T. Dwars, J. Haberland, I. Grassert, G. Oehme, U. Kragl, J. Mol. Catal. A 168 (2001) 81.

[17] S.C. Tsang, N. Zhang, L. Fellas, A.M. Steele, Catal. Today 61 (2000) 29.

[18] H. Sato, T. Ohtsu, I. Komasawa, J. Chem. Eng. Jpn. 35 (2002) 255.

[19] S.C. Tsang, K.M.K. Yu, A.M. Steele, J. Zhu, Q.J. Fu, Catal. Today 81 (2003) 573.

[20] A.B.R. Mayer, J.E. Mark, Col. Polym. Sci. 275 (1997) 333.

[21] M.V. Seregina, L.M. Bronstein, O.A. Platonova, D.M. Chernyshov, P.M. Valetsky, J. Hartmann, E. Wenz, M. Antonietti, Chem. Mater. 9 (1997) 923.

[22] E. Sulman, Yu. Bodrova, V. Matveeva, N. Semagina, L. Cerveny, V. Kurtc, L. Bronstein, O. Platonova, P. Valetsky, Appl. Catal. A 176 (1999) 75.

[23] L.M. Bronstein, D.M. Chernyshov, I.O. Volkov, M.G. Ezernitskaya, P.M. Valetsky, V.G. Matveeva, E.M. Sulman, J. Catal. 196 (2000) 302. 
[24] A. Molnar, A. Sarkany, M. Varga, J. Mol. Catal. A 173 (2001) 185.

[25] N.V. Semagina, A.V. Bykov, E.M. Sulman, V.G. Matveeva, S.N. Sidorov, L.V. Dubrovina, P.M. Valetsky, O.I. Kiselyova, A.R. Khokhlov, B. Stein, L.M. Bronstein, J. Mol. Catal. A 208 (2004) 273.

[26] M.L. Toebes, J.A. van Dillen, K.P. de Jong, J. Mol. Catal. 173 (2001) 75.

[27] M.J. Vincent, R.D. Gonzalez, Appl. Catal. A 217 (2001) 143.

[28] M.M. Telkar, C.V. Rode, V.H. Rane, R. Jaganathan, R.V. Chaudhari, Appl. Catal. A 216 (2001) 13.

[29] J.M. Winterbottom, H. Marwan, J. Viladevall, S. Sharma, S. Raymahasay, Stud. Surf. Sci. Catal. 108 (1997) 59.

[30] L.M. Bronstein, S.N. Sidorov, P.M. Valetsky, J. Hartmann, H. Colfen, M. Antonietti, Langmuir 15 (1999) 6256.

[31] R. Madon, M. Boudart, Ind. Eng. Chem. Fundam. 21 (1982) 438.

[32] L. Costa, A.M. Gad, G. Camino, G.G. Cameron, M.Y. Qureshi, Macromolecules 25 (1992) 5512.

[33] D. Dollimore, G.R. Heal, J. Appl. Chem. 14 (1964) 109.

[34] E. Joannet, C. Horny, L. Kiwi-Minsker, A. Renken, Chem. Eng. Sci. 57 (2002) 343.
[35] V. Holler, K. Radevik, I. Yuranov, L. Kiwi-Minsker, A. Renken, Appl. Catal. B 32 (2001) 143.

[36] L.M. Bronstein, D.M. Chernyshov, G.I. Timofeeva, L.V. Dubrovina, P.M. Valetsky, A.R. Khokhlov, Langmuir 15 (1999) 6195

[37] S. Sidorov, I. Volkov, V. Davankov, M. Tsyurupa, P. Valetsky, L. Bronstein, R. Karlinsey, J. Zwanziger, V. Matveeva, E. Sulman, N. Lakina, E. Wilder, R. Spontak, J. Am. Chem. Soc. 123 (2001) 10502.

[38] L. Kiwi-Minsker, E. Joannet, A. Renken, Chem. Eng. Sci. 59 (2004) 4919.

[39] U.K. Singh, M.A. Vannice, J. Catal. 191 (2000) 165.

[40] E.M. Sulman, Russ. Chem. Rev. 63 (1994) 923.

[41] M.M. Telkar, C.V. Rode, V.H. Rane, R. Jaganathan, R.V. Chaudhari, Book Abstr. EuropaCat V, Limerick, Ireland, September 2-7, 2001, p. 13-P-05.

[42] R.I. Macey, G.F. Oster, Berkeley Madonna ${ }^{\mathrm{TM}}$, 1997-2001.

[43] D. Brunel, N. Bellocq, P. Sutra, A. Cauvel, M. Lasperas, P. Moreau, F. Di Renzo, A. Galarneau, F. Fajula, Coord. Chem. Rev. 178-180 (1998) 1085

[44] M.M. Miller, D.G. Sherrington, J. Catal. 152 (1995) 377. 